\title{
Socioeconomic factors and lifestyles influencing the incidence of calcaneal fractures, a national population-based survey in China
}

\author{
Yanbin Zhu ${ }^{1,2+}$, Jia Li ${ }^{4 \dagger}$, Song Liu' ${ }^{1,2}$, Wei Chen ${ }^{1,2}$, Lin Wang ${ }^{1,2}$, Xiaolin Zhang ${ }^{5}$ and Yingze Zhang ${ }^{1,3^{*}}$
}

\begin{abstract}
Background: We aimed to do a national survey on the population-based incidence of calcaneal fracture in China. Methods: All the data on calcaneal fractures were available from the China National Fracture Survey (CNFS) between January and May in 2015. And in the CNFS, all eligible household members were sampled from 8 provinces, 24 urban cities and 24 rural counties in China, using stratified random sampling and the probability proportional to size method. Questionnaires were sent to every participant for data collection and quality control was accomplished by our research team members.

Results: A total of 512187 valid questionnaires were collected and relevant data were abstracted and analyzed. There were 59 patients with 62 calcaneal fractures occurring in 2014, indicating that the incidence was 11.5/100,000 person-years, $17.3 / 100,000$ in males, and 5.5/100,000 in females. BMI $\geq 28.0 \mathrm{~kg} / \mathrm{m}^{2}$, scarce meat consumption, smoking, alcohol consumption, average sleep time $<7 \mathrm{~h} /$ day, and previous history of fracture were identified as independent risk factors for calcaneal fracture.

Conclusions: Specific public health policies focusing on quitting smoking, decreasing alcohol consumption, and encouraging individuals to obtain sufficient sleep should be implemented. Reasonable meat consumption and maintaining a normal body weight should be emphasized in individuals, especially in those with previous fracture.
\end{abstract}

Keywords: Calcaneal fracture, Epidemiology, Population-based, Risk factor, China

\section{Introduction}

Calcaneal fracture was firstly described by Norris in the year 1839 and then was named by Malgaigne using his name in the year $1843[1,2]$. Calcaneal fracture was one of the common injuries in the department of emergency and orthopedics, and accounting for $60-78 \%$ of fractures in tarsal, $30 \%$ in foot, and $2-3.1 \%$ of all fractures [3-5]. As far as we know, only two studies were conducted to report the population-based incidence of calcaneal

\footnotetext{
* Correspondence: dryzzhang@126.com

${ }^{\dagger}$ Yanbin Zhu and Jia Li contributed equally to this work.

'Department of Orthopaedic Surgery, The Third Hospital of Hebei Medical

University, NO.139 Ziqiang Road, Shijiazhuang, Hebei 050051, People's Republic of China

${ }^{3}$ Chinese Academy of Engineering, Beijing 100088, People's Republic of China

Full list of author information is available at the end of the article
}

fracture [5, 6]. In the former one [5], authors used the Finland National Hospital Discharge Register to assess the epidemiology of calcaneal fractures and reported the incidence of 12.5 in males and 3.9 in females per 100,000 persons, respectively. However, only hospitalized patients selected as study objects inevitably result in the underestimation of incidence rate of calcaneal fractures. In the latter one from Edinburgh [6], authors reported the annual incidence of calcaneal fracture was 16.5 and 6.3 per 100,000 in males and females, and concluded males were more likely to sustain this injury relative to females. But the methodological design as single hospital might compromise the results, although the sample size was not small (752 fractures in 697 patients). Another Finnish study presented rising incidence of low-trauma foot and calcaneus fractures among adults > 50 years in 1970-

(c) The Author(s). 2019 Open Access This article is distributed under the terms of the Creative Commons Attribution 4.0 International License (http://creativecommons.org/licenses/by/4.0/), which permits unrestricted use, distribution, and reproduction in any medium, provided you give appropriate credit to the original author(s) and the source, provide a link to the Creative Commons license, and indicate if changes were made. The Creative Commons Public Domain Dedication waiver (http://creativecommons.org/publicdomain/zero/1.0/) applies to the data made available in this article, unless otherwise stated. 
2005, but did not analyze the incidence of calcaneal fractures alone [7]. However, extrapolation of conclusions obtained from these studies to our population and implementation in our routine clinical evaluation might not be valid due to differences in ethnic groups, economic development, culture practice, and lifestyles among different countries. Furthermore, we have not found any previous studies that aimed to investigate the socioeconomic risk factors associated with calcaneal fractures.

Currently, the National Health Services Survey (NHSS) is the epidemiologic database of the national level in China for the collection of data on self-reported fractures at 2 weeks before the surgery. However, we were unable to obtain any information on less severe fractures treated by conservative methods. Furthermore, this national survey system only collected the most basic data on fractures (e.g., age, gender, and fracture occurrence timing), but without any information on type of fracture, body site, injury mechanisms, and related potential risk factor (socioeconomic and lifestyles).

Given above, we designed and performed the China National Fracture Study (CNFS) in 2015 with aims to investigate the population-based incidence of traumatic fracture of the trunk, arms, or legs and associated socioeconomic risk factors and lifestyles. The overall results have been published recently [8]. In this study, we extracted related data on calcaneal fractures from the CNFS database and aimed (1) to report the national population-based incidence of calcaneal fracture in China and (2) to explore the associated risk factors in term of demographics, socioeconomics, and lifestyles.

\section{Methods}

\section{Sampling method}

The entire sampling process of CNFS was completed with combined use of optimum allocation and random stratified and probability proportionate to size (PPS) sampling method. During the first phase, 8 provinces (municipalities) were initially selected from 31 provinces (municipalities or autonomous regions) in mainland China based on socioeconomic development and climate, using stratified random sampling method. And within each targeted province (municipalities), sampling was done separately in urban and rural areas (Table 1).

For urban areas, using the optimum allocation and random stratified and probability proportional to size method, we selected a certain number of streets ranging from one to six in each sampled city and a certain number ranging from one to ten neighborhood communities from each chosen street based on the geographical location from west to east on the electronic map. The total number of families in each neighborhood community was determined by the average number of household members according to the latest official census data in
China. All members of eligible families to be invited to participate in this study must have lived in their current residence for at least 6 months.

For rural areas, we sampled 1-5 counties in each selected province and then in each county, 1-8 towns were selected. In each town, 1-14 administrative villages were sampled. The sampling process was completed using the probability proportional to size method. In each village, households were calculated and selected based on probability proportional to size principles. Similarly, as in urban areas, all members of eligible families to be invited to participate in this study must have lived in their current residence for at least 6 months.

\section{Participants and survey}

In principle, eligible household members must be personally interviewed by trained research team members. However, for preschool and primary school children, their information should be provided by their guardians in order to ensure data accuracy. For participants who remained non-contactable after repeated visits, telephone surveys had to be used. For any member in selected household who refused to participate, an alternative household was randomly selected from the candidate list.

A standardized questionnaire was administered by our trained research team for data collection. The detailed information included age, sex, Chinese ethnic nationality, marital status, residence, income status, occupation, lifestyles (smoking, alcohol drinking, tea, coffee, and carbonated beverages and daily consumption of meat, protein product, and dairy products) for all participants, age of menopause, and the number of births for women. Individuals who had calcaneal fractures between January 1 and December 31, 2014, then must answer a more detailed accessory questionnaire regarding the fracture occurrence, date and place, and injury mechanism. In addition, they were asked to provide medical records of the index injury, including radiographs, diagnostic reports, and medical reports. And if these data were not available, the survey team paid for individual participants to obtain a new radiograph of their reported calcaneus at a local hospital for reappraisal.

Eight quality control teams were established (one per province) to check for the quality of related data collection. The CNFS was approved by the Institutional Review Board of the 3rd Hospital of Hebei Medical University and written informed consent was obtained from each participant before data collection.

\section{Definition of variables of interest}

Individuals were divided into Han ethnicity and others including all the national minority ethnicity. The body mass index (BMI) was calculated as weight divided by 
Table 1 National incidence of calcaneal fractures among Chinese population by demographic, socioeconomic, and geographic factors in 2014

\begin{tabular}{|c|c|c|c|c|c|c|c|}
\hline \multirow[t]{2}{*}{ Items } & \multirow{2}{*}{$\begin{array}{l}\text { Sample } \\
\text { size }\end{array}$} & \multicolumn{2}{|l|}{ Male } & \multicolumn{2}{|c|}{ Female } & \multicolumn{2}{|l|}{ Total } \\
\hline & & $\overline{\text { Case }}$ & Incidence $(1 / 100000)$ & Case & Incidence $(1 / 100000)$ & Case & Incidence $(1 / 100000)$ \\
\hline Overall & 512187 & 45 & $17.3(12.3-22.4)$ & 14 & $5.5(2.6-8.4)$ & 59 & $11.5(8.6-14.5)$ \\
\hline \multicolumn{8}{|l|}{ Age (years) } \\
\hline \multirow[t]{2}{*}{$0-14$} & 81166 & 4 & 9 & 1 & 2.7 & 5 & 6.2 \\
\hline & & & $(0.2-17.9)$ & & & & $(0.8-11.6)$ \\
\hline \multirow[t]{2}{*}{$15-44$} & 236206 & 18 & 15.2 & 4 & 3.4 & 22 & 9.3 \\
\hline & & & $(8.2-22.3)$ & & $(0.1-6.7)$ & & $(5.4-13.2)$ \\
\hline \multirow[t]{2}{*}{$45-64$} & 138533 & 19 & 27.5 & 5 & 7.2 & 24 & 17.3 \\
\hline & & & $(15.1-39.8)$ & & $(0.9-13.5)$ & & $(10.4-24.3)$ \\
\hline \multirow[t]{2}{*}{$65+$} & 56282 & 4 & 14.2 & 4 & 14.2 & 8 & 14.2 \\
\hline & & & $(0.3-28.2)$ & & $(0.3-28.1)$ & & $(4.4-24.1)$ \\
\hline$p$ value for trend test & 512187 & 0.13 & & 0.028 & & 0.021 & \\
\hline \multicolumn{8}{|l|}{ Ethnicity } \\
\hline \multirow[t]{2}{*}{ Han } & 477508 & 43 & 17.8 & 14 & 5.9 & 57 & 11.9 \\
\hline & & & $(12.5-23.1)$ & & $(2.8-9.1)$ & & $(8.8-15)$ \\
\hline \multirow[t]{2}{*}{ Others } & 34679 & 2 & 11.4 & 0 & 0 & 2 & 5.8 \\
\hline & & & $(-4.4-27.1)$ & & & & \\
\hline$p$ value for difference test & 512187 & 0.533 & & 0.314 & & 0.437 & \\
\hline \multicolumn{8}{|l|}{ Region } \\
\hline \multirow[t]{2}{*}{ East } & 232998 & 24 & 20.1 & 7 & 6.2 & 31 & 13.3 \\
\hline & & & $(12.1-28.1)$ & & $(1.6-10.7)$ & & $(8.6-18)$ \\
\hline \multirow[t]{2}{*}{ Central } & 99109 & 7 & 14.1 & 3 & 6.1 & 10 & 10.1 \\
\hline & & & $(3.6-24.5)$ & & & & $(3.8-16.3)$ \\
\hline \multirow[t]{2}{*}{ West } & 180080 & 14 & 15.5 & 4 & 4.5 & 18 & 10 \\
\hline & & & $(7.4-23.6)$ & & $(0.1-8.8)$ & & $(5.4-14.6)$ \\
\hline$p$ value for difference test & 512187 & 0.602 & & 0.863 & & 0.553 & \\
\hline \multicolumn{8}{|l|}{ Urbanization } \\
\hline \multirow[t]{2}{*}{ Urban area } & 203101 & 12 & 11.7 & 6 & 6 & 18 & 8.9 \\
\hline & & & $(5.1-18.3)$ & & $(1.2-10.8)$ & & $(4.8-13)$ \\
\hline \multirow[t]{2}{*}{ Rural area } & 309086 & 33 & 21 & 8 & 5.3 & 41 & 13.3 \\
\hline & & & $(13.8-28.2)$ & & $(1.6-8.9)$ & & $(9.2-17.3)$ \\
\hline$p$ value for difference test & 512187 & 0.078 & & 0.814 & & 0.151 & \\
\hline \multicolumn{8}{|l|}{ Education } \\
\hline \multirow[t]{2}{*}{ Illiterate } & 74937 & 9 & 26.1 & 7 & 17.3 & 16 & 21.4 \\
\hline & & & $(9.1-43.2)$ & & $(4.5-30.1)$ & & $(10.9-31.8)$ \\
\hline \multirow[t]{2}{*}{ Primary school } & 158970 & 24 & 29.9 & 2 & 2.5 & 26 & 16.4 \\
\hline & & & $(17.9-41.9)$ & & & & $(10.1-22.6)$ \\
\hline \multirow[t]{2}{*}{ Junior high school } & 121415 & 7 & 11.4 & 4 & 6.7 & 11 & 9.1 \\
\hline & & & $(3-19.8)$ & & $(0.1-13.2)$ & & $(3.7-14.4)$ \\
\hline Senior high school or above & 40841 & 4 & 18.5 & 0 & 0 & 4 & 9.8 \\
\hline & & & $(0.4-36.7)$ & & & & $(0.2-19.4)$ \\
\hline$p$ value for trend test & 396163 & 0.104 & & 0.036 & & 0.023 & \\
\hline
\end{tabular}


the square of height, and was grouped based the reference criteria suited to Chinese people: underweight, < 18.5; normal, 18.5-23.9; overweight, 24-27.9; obesity, > = 28 [8, 9]. Daily diet and drinking including meat and products, bean products, milk and dairy products, coffee, tea, and carbonated beverages were divided into 5 groups based on the frequency of consumption: never, always (at least 1 per day), often (1/day-1/week), occasionally (1/week-1/ month), and seldom $(<1 /$ month). Calcium or vitamin $D$ supplement was defined as positive if participants acknowledged they received calcium or vitamin $\mathrm{D}$ or both related medicine or nourishment at least 1 month before the calcaneal fracture occurrence. Urbanization was divided into 2 groups: (1) rural area (village) and (2) urban areas (cities of levels).

\section{Statistical analysis}

Incidence rates for calcaneal fractures were estimated for the overall population and for subgroups such as age, ethnics, region, education level, and urbanization level, stratified by gender. For unordered categorical variables such as region, urbanization, and ethnics, the chi-square test was used to test the difference. For ordered categorical variables such as age and education level, we entered the related data as a continuous variable into a univariate logistic regression model to assess the incidence trend.

Case group was defined as adult patients sustaining calcaneal fractures in 2014, and control group was defined as adult individuals without any fracture in 2014. Chi-square test was used to investigate the potential correlations between calcaneal fractures and various factors of interest. Finally, multivariate logistic regression models were used to explore the independent risk factors associated with calcaneal fractures. $P<0.05$ was set as the statistical significance level. Odd ratio (OR) values and corresponding 95\% confidence interval (95\% CI) were used to indicate the strength of correlation of risk factor. The HosmerLemeshow test was used to examine goodness-of-fit of the final model and a $p$ value $>0.05$ indicated an acceptable fitness. SPSS 19.0 was used to perform all the analyses (SPSS Inc., Chicago, IL, USA).

\section{Results}

During the survey, a total of 512,187 valid questionnaires were collected and relevant data were abstracted and analyzed. Through the year 2014, 1763 patients sustained traumatic fractures (1833 fractures). Of them, there were 59 patients with 62 calcaneal fractures, indicating that the incidence rate was 11.5 (95\%CI, 8.6-14.5) per 100 , 000 person-years. There were 45 males and their median age was 45 years and the corresponding incidence rate was $17.3(95 \% \mathrm{CI}, 12.3-22.4)$ per 100,000 person-years; there were 14 females sustaining calcaneal fractures with median age of 60 years, and the corresponding incidence was 5.5 (95\% CI, 2.6-8.4) per 100,000 person-years.

Fall from a height was the most common cause, leading to $47.5 \%(28 / 59)$ of calcaneal factures, and was followed by slip, trip, or fall from standing height, chairs, or stairs (42.4\%, 25/59); traffic accidents $(5.1 \%, 3 / 59)$; and crushing injuries $(5.1 \%, 3 / 59)$ (Table 2). In the middle-aged and elderly patients, $60 \%(15 / 25)$ of the injuries were caused by low-energy slip, trip, or fall from standing height, chairs, or stairs. In terms of occurrence place of calcaneal fracture, home and building site were the first two common sites which accounted for $71.2 \%$ of the overall injuries. Besides, work unit was also an important place that should be considered, where $15.3 \%$ (9/59) of calcaneal fractures happened (Table 3).

Table 1 presented the population-based incidence rates of calcaneal fractures in overall populations and subgroups based on democratic and socioeconomic characteristics, stratified by gender. There was no significant difference in incidence between those of Han ethnicity and all other ethnicities combined, nor was there any significant difference according to geographical region, urbanization, or education, either for overall population or any gender (Table 1). Stratified by age, males of 45-64 years and females of $\geq 65$ years had the highest incidence rate (27.5 and 14.2 per 100,000 person-years), respectively. The trend difference of incidence rate by age in females and overall population approach to significance $(p=0.028 ; p=0.021)$, but was non-significant in males $(p=0.130)$. Stratified by education level, the illiterate in females and males with primary school level had the highest incidence in respective subgroup, and the trend difference test demonstrated the significant result in females $(p=0.036)$ but not in males $(p=0.104)$

Table 4 presented the detailed results of univariate chi-square test between case and control group in adults ( $\geq 15$ years). We could find that there were significant differences between calcaneal fractures and controls in term of gender $(p<0.001)$, BMI $(p=0.015)$, education level $(p=0.038)$, occupation $(p=0.032)$, meat and product $(p<0.001)$, smoking status $(p<0.001)$, alcohol consumption $(p<0.001)$, sleep time per day $(p<0.001)$, calcium or vitamin D supplement or both $(p=0.025)$, and history of fracture $(p<0.001)$. And in other variables, we did not observe the significant differences, such as age and region.

Table 5 summarized independent risk factors for calcaneal fractures in adults, after adjustment for other confounding variables. BMI $\geq 28.0$ significantly increased the risk of calcaneal fracture by 3.04 (95\% CI, 1.25-7.38) times, compared to the normal BMI (18.5-23.9). Patients with previous history of fracture had an increased risk of calcaneal fracture by 3.58 times $(95 \%$ CI, $1.52-$ 8.43). And compared to those having enough sleep time 
Table 2 The causal mechanisms for calcaneal fractures in China in 2014 (n, \%)*

\begin{tabular}{|c|c|c|c|c|}
\hline \multirow[t]{2}{*}{ Injury mechanism } & \multirow{2}{*}{$\begin{array}{l}\text { Children } \\
\text { (0-14 years) }\end{array}$} & \multicolumn{2}{|c|}{ Adult ( $\geq 15$ years) } & \multirow[t]{2}{*}{ Total } \\
\hline & & Male & Female & \\
\hline Fall from heights & $2(66.7)$ & $13(41.9)$ & $13(52.0)$ & $28(47.5)$ \\
\hline Slip, trip, or fall from standing height, chairs, or stairs & $1(33.3)$ & $16(51.6)$ & $8(32.0)$ & $25(42.4)$ \\
\hline Traffic accident & 0 & 0 & $3(12.0)$ & $3(5.1)$ \\
\hline Crushing injury & 0 & $2(6.5)$ & $1(4.0)$ & $3(5.1)$ \\
\hline Sum & $3(5.1)$ & $31(52.5)$ & $25(42.4)$ & $59(100.0$ \\
\hline
\end{tabular}

( $\geq 7 \mathrm{~h}$ /day), average sleep time $<7 \mathrm{~h}$ /day increased the risk of calcaneal fracture by 2.85 times $(95 \% \mathrm{CI}, 1.63-$ 4.95). In addition, bad lifestyles such as smoking and alcohol consumption were identified as significant risk factors and increased the 2.54 and 2.51-time risk of calcaneal fractures, respectively.

In the final multivariate logistic regression model, the Hosmer-Lemeshow test demonstrated the adequate fitness $\left(X^{2}=3.253, P=0.917\right)$.

\section{Discussion}

Currently, optimal management of calcaneal fractures is controversial [10], and compartment syndrome of foot is one of the most important implications after injury, with high risk of morbidity and poor outcome, including persistent neurologic deficits or amputation [11]. Extensive differences in the epidemiological characteristics of calcaneal fractures among geographic regions, ethnic groups, races, and gender have been reported [5-7, 12], and the results should be for references only but not be directly applied in Chinese policy makers and clinical practices. In the present study, we used the data from CNFS database to resolve this issue and the results showed that the incidence rate of calcaneal fracture was $11.5 / 100,000$ person-years with $17.3 / 100,000$ personyears in males and 5.5/100,000 person-years in females. Fall from height remained in the first place in the causes of calcaneal fracture occurrence, closely followed by skip, trip, or fall from chair or stairs. Over $70 \%$ of the injuries occurred at home and building site. In adults, BMI

Table 3 The place of calcaneal fracture occurrence in $2014(n, \%)^{*}$

\begin{tabular}{lllll}
\hline $\begin{array}{l}\text { Place of } \\
\text { fracture } \\
\text { occurrence }\end{array}$ & Children & \multicolumn{2}{l}{ Adult $(\geq 15$ years $)$} & Total \\
\cline { 3 - 4 } & & Male & Female & \\
\hline Home & $3(60.0)$ & $12(29.3)$ & $8(61.5)$ & $23(39.0)$ \\
Work unit & $1(20.0)$ & $7(17.1)$ & $1(7.7)$ & $9(15.3)$ \\
Building site & 0 & $17(41.5)$ & $2(15.4)$ & $19(32.2)$ \\
Road & 0 & $1(2.4)$ & $2(15.4)$ & $3(5.1)$ \\
Expressway & 0 & $2(4.9)$ & 0 & $2(3.4)$ \\
School & $1(20.0)$ & $1(2.4)$ & 0 & $2(3.4)$ \\
Others & 0 & $1(2.4)$ & 0 & $1(1.7)$ \\
Sum & $5(8.5)$ & $41(69.5)$ & $13(22.0)$ & $59(100.0)$ \\
\hline
\end{tabular}

$\geq 28.0$, seldom or no consumption of meat and product, smoking, alcohol consumption, average sleep time $<7$ $\mathrm{h} /$ day, and previous history of fracture significantly increased the risk of calcaneal fractures.

The incidence rate of calcaneal fractures reported in this study was consistent with that in a UK study [6] but slightly higher than the study in Finland [5]. The former one reported the incidence of 11.5 per 100,000 for overall population, $16.5 / 100,000 /$ year in males and 6.26/100, $000 /$ year in females, which were all similar as ours [6]. However, regarding the injury mechanism, the authors reported falls from a height (71.5\%) as the first place, and $64.3 \%$ of these were from $6 \mathrm{ft}$ and above, which was considerably higher than ours (47.5\%). We thought this great gap mainly lied in the patient source in their study, all patients were from a level-1 trauma center and presented with more severe injuries necessitating hospitalization and operation. In contrast, in our study, patients were sampled based on overall population and therefore were more representative. In fact, results in this study showed that a certain proportion $(60 \%, 15 / 25)$ of patients were caused by low-energy slip or fall from low height such as chair, bed, or stairs, in the elderly In the latter study [5], authors reported the slightly lower incidence rate $(12.5 / 100,000$ in males and 3.9/100,000 in females) of hospitalization patients in adults and concluded the incidence remained relatively stable during the past 26 years. In addition, authors observed that male patients with calcaneal fractures were much younger than females (43 vs 61), which was similar as ours (median, 45 years in males and 60 years in females). We infer that this might be related to the high-energy activities in males and relatively poorer bone quality and mass in females.

In the current studies, unhealthy lifestyles or bad habits such as smoking, alcohol consumption, and sleeping time less than $7 \mathrm{~h}$ per day was identified as independent risk factor for calcaneal fractures in adults. Alcohol consumption as a risk factor for traumatic fracture had been well recognized in the literature [13, 14]. Scholes et al. suggested consuming more than 8 units of alcohol for men or more than 6 units for women in the past week increased the 1.65-time and 2.07-time risk of fractures in individuals $\geq 55$ years [13]. The underlying 
Table 4 Detailed results of univariate analysis for variables of interest

\begin{tabular}{|c|c|c|c|}
\hline Variables & $\begin{array}{l}\text { Case, } \\
n=54(\%)\end{array}$ & $\begin{array}{l}\text { Control, } \\
n=429,375(\%)\end{array}$ & $p$ \\
\hline Gender & & & $<0.001$ \\
\hline Male & $41(75.9)$ & $214,501(50)$ & \\
\hline Female & $13(24.1)$ & $214,874(50)$ & \\
\hline \multicolumn{4}{|l|}{ Age (year) } \\
\hline $15-44$ & $22(40.7)$ & $235,657(54.9)$ & 0.101 \\
\hline $45-64$ & $24(44.4)$ & 137,779 (32.1) & \\
\hline$\geq 65$ & $8(14.8)$ & $55,939(13)$ & \\
\hline Region & & & 0.728 \\
\hline Eastern & $27(50)$ & $193,223(45)$ & \\
\hline Middle & $9(16.7)$ & $85,630(19.9)$ & \\
\hline Western & $18(33.3)$ & $150,522(35.1)$ & \\
\hline Urbanization & & & 0.213 \\
\hline Rural area & $17(31.5)$ & $258,563(60.2)$ & \\
\hline Urban area & $37(68.5)$ & $170,812(39.8)$ & \\
\hline Ethnicity & & & 0.158 \\
\hline Han & $53(98.1)$ & 400,874 (93.4) & \\
\hline Other & $1(1.9)$ & $28,501(6.6)$ & \\
\hline BMI & & & 0.015 \\
\hline $18.5-23.9$ & $27(50)$ & $282,433(65.8)$ & \\
\hline $24-27.9$ & $18(33.3)$ & $102,964(24)$ & \\
\hline$\geq 28$ & $6(11.1)$ & $17,730(4.1)$ & \\
\hline$<18.5$ & $3(5.6)$ & $26,248(6.1)$ & \\
\hline Education & & & 0.038 \\
\hline Illiterate & $16(29.6)$ & $74,774(17.4)$ & \\
\hline Primary school & $23(42.6)$ & $162,924(37.9)$ & \\
\hline Junior high school & $11(20.4)$ & $134,891(31.4)$ & \\
\hline Senior high school or above & $4(7.4)$ & $56,786(13.2)$ & \\
\hline Occupation & & & 0.032 \\
\hline Unemployed & $1(1.9)$ & $32,590(7.6)$ & \\
\hline Office worker & $2(3.7)$ & $61,747(14.4)$ & \\
\hline Manual worker & $25(46.3)$ & $148,165(34.5)$ & \\
\hline Farmer & $19(35.2)$ & $105,960(24.7)$ & \\
\hline Retired & $4(7.4)$ & $30,197(7)$ & \\
\hline Students & $1(1.9)$ & $34,833(8.1)$ & \\
\hline Other & $2(3.7)$ & $15,883(3.7)$ & \\
\hline \multicolumn{4}{|l|}{ Meat and product } \\
\hline Never or seldom & $9(16.7)$ & $22,000(5.1)$ & $<0.001$ \\
\hline Always & $28(51.9)$ & $216,500(50.4)$ & \\
\hline Often & $9(16.7)$ & $130,155(30.3)$ & \\
\hline Occasionally & $8(14.8)$ & $60,720(14.1)$ & \\
\hline Seldom & $9(16.7)$ & $19,448(4.5)$ & \\
\hline Dairy and product & & & 0.944 \\
\hline
\end{tabular}

Table 4 Detailed results of univariate analysis for variables of interest (Continued)

\begin{tabular}{|c|c|c|c|}
\hline Variables & $\begin{array}{l}\text { Case, } \\
n=54(\%)\end{array}$ & $\begin{array}{l}\text { Control, } \\
n=429,375(\%)\end{array}$ & $p$ \\
\hline Always & $9(16.7)$ & $69,907(16.3)$ & \\
\hline Often & $8(14.8)$ & $76,218(17.8)$ & \\
\hline Occasionally & $8(14.8)$ & $72,971(17)$ & \\
\hline Bean product & & & 0.099 \\
\hline Never or seldom & $7(13.0)$ & 47,925 (11.1) & \\
\hline Always & $13(24.1)$ & $80,682(18.8)$ & \\
\hline Often & $16(29.6)$ & $200,433(46.7)$ & \\
\hline Occasionally & $18(33.3)$ & $100,335(23.4)$ & \\
\hline Alcohol consumption & & & $<0.001$ \\
\hline No & $19(35.2)$ & $289,344(67.4)$ & \\
\hline Yes & $35(64.8)$ & $140,031(32.6)$ & \\
\hline Cigarette smoking & & & $<0.001$ \\
\hline No & $24(44.4)$ & $324,652(75.6)$ & \\
\hline Yes & $30(55.6)$ & $104,723(24.4)$ & \\
\hline Carbonate beverages & & & 0.265 \\
\hline Never or seldom & $33(61.1)$ & $310,164(72.3)$ & \\
\hline Always & $1(1.9)$ & $4766(1.1)$ & \\
\hline Often & $3(5.6)$ & $58,481(13.6)$ & \\
\hline Occasionally & $6(11.1)$ & $55,964(13)$ & \\
\hline Coffee & & & 0.160 \\
\hline No & $53(98.1)$ & 401,055 (93.4) & \\
\hline Yes & $1(1.9)$ & $28,320(6.6)$ & \\
\hline Tea & & & 0.093 \\
\hline Never or seldom & $23(42.6)$ & $255,980(59.6)$ & \\
\hline Always & 18 (33.3) & $103,425(24.1)$ & \\
\hline Often & $8(14.8)$ & $41,056(9.6)$ & \\
\hline Occasionally & $5(9.3)$ & $28,914(6.7)$ & \\
\hline Living circumstance & & & 0.523 \\
\hline Single-storey house & $24(44.4)$ & 170,315 (39.7) & \\
\hline House $\leq 7$ storey & $28(51.9)$ & $227,535(53)$ & \\
\hline House $>7$ storey & $2(3.7)$ & $31,525(7.3)$ & \\
\hline \multicolumn{2}{|c|}{ Calcium or vitamin D supplement or both } & & 0.025 \\
\hline No & $47(87)$ & $404,323(94.2)$ & \\
\hline Yes & $7(13)$ & $25,052(5.8)$ & \\
\hline \multicolumn{2}{|c|}{ Average sleep time (hours) per day } & & $<0.001$ \\
\hline$\geq 7$ & $20(37)$ & $280,212(65.3)$ & \\
\hline$<7$ & $34(63)$ & $149,163(34.7)$ & \\
\hline Previous history of frac & & & $<0.001$ \\
\hline No & $48(88.9)$ & $419,666(97.7)$ & \\
\hline Yes & $6(11.1)$ & $9709(2.3)$ & \\
\hline
\end{tabular}


Table 5 Results of multivariate logistic regression of risk factors for calcaneal fractures

\begin{tabular}{lllll}
\hline Variables & Exp (B) & \multicolumn{2}{l}{$95 \% \mathrm{Cl}$} & $p$ \\
\cline { 5 - 5 } & & Lower limit & Upper limit & \\
\hline BMI & & & & \\
$18.5-23.9$ & Reference & & & \\
$<18.5$ & 1.45 & 0.44 & 4.77 & 0.546 \\
$24-27.9$ & 1.56 & 0.86 & 2.84 & 0.144 \\
$\geq 28.0$ & 3.04 & 1.25 & 7.38 & 0.014 \\
Meat and product consumption & & & \\
Always & Reference & & & \\
Often & 0.529 & 0.250 & 1.122 & 0.097 \\
Occasionally & 1.022 & 0.465 & 2.245 & 0.957 \\
Seldom or never & 3.182 & 1.494 & 6.779 & 0.003 \\
Smoking & 2.54 & 1.41 & 4.58 & 0.002 \\
Alcohol consumption & 2.51 & 1.36 & 4.64 & 0.003 \\
Previous fracture history & 3.58 & 1.52 & 8.43 & 0.003 \\
Sleep < 7 h/day & 2.85 & 1.63 & 4.95 & $<0.001$ \\
\hline
\end{tabular}

mechanism might be related to metabolic effects and alcohol-related falls [13, 14]. Stone et al. [15] reported that women who slept for $5 \mathrm{~h}$ or less or $5-7 \mathrm{~h}$ had the higher risk of frequent falls, compared to those with adequate sleep (7-8 h/day). And Holmberg et al. [16] got similar findings in males that sleep disturbances contributed to the increased risk in most fractures. Tobacco consumption was identified to have a significant negative effect on bone mineral density and is a risk factor for fractures in general $[17,18]$. Cornuz et al. [17] did a large study of 116229 female aged 34-59 years with up to 12-year follow-up and found an increased relative risk of 1.3 (95\% CI 1.0-1.7) for hip fractures in current smokers when compared with non-smokers. A Finland study including 11,798 women aged $47-56$ years with follow-up of 5 years showed smokers with less than 20 cigarettes per day and $\geq 20$ cigarettes per day increased the 1.73-time and 2.94-time risk of ankle fractures, respectively [19]. In addition, Cornuz et al. suggested that quitting smoking could at least reduce $30 \%$ of the fractures, at 10-year follow-up after quitting [17]. Therefore, healthy lifestyles like decreased alcohol consumption, non-smoking or quitting smoking, and adequate sleep duration should clearly be advocated to reduce fracture risk.

Obesity (BMI $\geq 28.0)$ was identified as a significant risk factor for calcaneal fracture and compared to those with normal BMI (18.5-23.9), obese individuals had the 3time risk of calcaneal fracture. We suggested that heavy weight plays an important role in calcaneal fracture occurrence, which brought greater press on calcaneus when moving or falls from height or standing height, especially in young and middle-aged patients. Nielson et al. and Compston et al. suggested the reduced physical mobility and repeated falls were at least partially responsible for fractures in elderly patients with decreased bone mass $[20,21]$. In addition, obesity-related chronic morbidities as diabetes mellitus and cerebrovascular diseases predisposed to the fractures [20]. History of previous fracture as a risk factor for the subsequent fracture had been well identified in literature and was reidentified in this study. In a meta-analysis by Klotzbuecher et al. [22], authors concluded history of prior fracture at any site was an important risk factor for future fractures and the risk of future fractures appeared to increase with the number of prior fractures. Kanis et al. drew the similar conclusion in a meta-analysis that previous history of fracture conferred an increased 1.86time risk of subsequent fracture of any site beyond that explanation by measurement of BMD [23]. Reasonable diet with balance portion of meat and vegetables was necessitated for bone health, and meat consumption $<1$ time/month was identified as a risk factor for calcaneal fracture. The underlying mechanism might be related to the animal protein and minerals in meat that were necessary to human, but remains to be investigated.

This is currently the largest questionnaire survey of incidence and risk factors for calcaneal fractures. Despite this, some potential limitations must be mentioned. Firstly, the retrospective nature of this study had its intrinsic weakness in accuracy of collected data, which might incur recall biases. Secondly, the results of patients' self-report on fracture and individual life styles might be affected due to manners or customs. Thirdly, the incidence rate of calcaneal fracture could be underestimated, as we could not capture data on the individual who had died in this index injury or coexisting diseases or complications.

In summary, the current study provided detailed information about the national population-based incidence, characteristics, and related risk factors of calcaneal fractures, which could be used as reference data for healthcare policy makers and health consultation and prevention for individuals. Specific public health policies focusing on decreasing alcohol consumption, quitting smoking, and encouraging individuals to obtain sufficient sleep should be implemented. Reasonable meat consumption and maintaining a normal body weight should be emphasized in individuals, especially in those with history of previous history.

\section{Abbreviations}

BMD: Bone mineral density; BMI: Body mass index; CNFS: China national fracture study; NHSS: National health services survey; OR: Odd ratio; PPS: Probability proportionate to size 


\section{Authors' contributions}

YZZ designed the study; WC and LW searched relevant studies on the subject; SL and XLZ analyzed and interpreted the data; YBZ and JL wrote the manuscript and $Y Z Z$ approved the final version of the manuscript. All authors read and approved the final manuscript.

\section{Funding}

This study was supported by the Hebei Province Medical Science Special Major Projects Research Fund

\section{Availability of data and materials}

The datasets generated and/or analyzed during the current study are not in public but are available from the corresponding author on reasonable request.

\section{Ethics approval and consent to participate}

This study was approved by the Institutional Review Board of Third Hospital of Hebei Medical University and received written consent from all the study participants.

\section{Consent for publication}

Written informed consent was obtained from each patients' parents for the publication of this report and the accompanying images.

\section{Competing interests}

The authors declare that they have no competing interests

\section{Author details}

'Department of Orthopaedic Surgery, The Third Hospital of Hebei Medical University, NO.139 Ziqiang Road, Shijiazhuang, Hebei 050051, People's Republic of China. ${ }^{2}$ Key laboratory of biomechanics of Hebei Province, Shijiazhuang, Hebei 050051, People's Republic of China. ${ }^{3}$ Chinese Academy of Engineering, Beijing 100088, People's Republic of China. ${ }^{4}$ Department of Orthopaedic Surgery, The First Hospital of Hebei Medical University, Shijiazhuang, Hebei 050031, People's Republic of China. ${ }^{5}$ Department of statistics and epidemiology, Hebei Medical University, Shijiazhuang, Hebei 050000, People's Republic of China.

Received: 12 August 2019 Accepted: 27 November 2019

Published online: 10 December 2019

\section{References}

1. Swanson SA, Clare MP, Sanders RW. Management of intra-articular fractures of the calcaneus. Foot Ankle Clin. 2008:13(4):659-78.

2. Coughlin MJ, Mann RA, Saltzman CL. Surgery of the foot and ankle. 8th ed, 2008; pp 461-462.

3. Zhang Y. Clinical epidemiology of orthopaedic trauma, 2 ed., Thieme, Stuttgart, 2012.

4. Cohen Z, Volpin G, Shtarker H. Surgical treatment of displaced calcaneal fractures: Springer Berlin Heidelberg. 2011;199-214 p.

5. Haapasalo H, Laine HJ, Mäenpää H, Wretenberg P, Kannus P, et al. Epidemiology of calcaneal fractures in Finland. Foot Ankle Surg. 2017:23:321-4.

6. Mitchell MJ, Mckinley JC, Robinson CM. The epidemiology of calcaneal fractures. Foot. 2009:19(4):197-200.

7. Kannus P, Niemi S, Palvanen $M$, Sievänen $H$, Parkkari J, et al. Rising incidence of low-trauma fractures of the calcaneus and foot among Finnish older adults. J Gerontol A Biol Sci Med Sci. 2008;63(6):642-5.

8. Chen W, Lv H, Liu S, Liu B, Zhu Y, et al. National incidence of traumatic fractures in China: a retrospective survey of 512187 individuals. Lancet Glob Health. 2017;5(8):e807-17.

9. Zhu Y, Liu S, Zhang X, Chen W, Zhang Y. Incidence and risks for surgical site infection after adult tibial plateau fractures treated by ORIF: a prospective multicentre study. Int Wound J. 2017;14:982-8.

10. Gougoulias N, Khanna A, McBride DJ, Maffulli N. Management of calcaneal fractures: systematic review of randomized trials. Br Med Bull. 2009;92:153-67.

11. Lutter C, Schöffl V, Hotfiel T, Simon M, Maffulli N. Compartment syndrome of the foot: an evidence-based review. J Foot Ankle Surg. 2019;58(4):632-40.

12. Tadros AMA, Eid HO, Abu-Zidan FM. Epidemiology of foot injury in a highincome developing country. Injury. 2010;41(2):137-40.
13. Scholes S, Panesar S, Shelton NJ, Francis RM, Mirza S, et al. Epidemiology of lifetime fracture prevalence in England: a population study of adults aged 55 years and over. Age Ageing. 2014;43(2):234-40.

14. Clark MK, Sowers MF, Dekordi F, Nichols S. Bone mineral density and fractures among alcohol-dependent women in treatment and in recovery. Osteoporos Int. 2003;14(5):396-403.

15. Stone KL, Ancoliisrael S, Blackwell T, Ensrud KE, Cauley JA, et al. Actigraphymeasured sleep characteristics and risk of falls in older women. Arch Intern Med. 2008:168:1768-75.

16. Holmberg AH, Johnell O, Nilsson PM, Nilsson J, Berglund G, et al. Risk factors for fragility fracture in middle age. A prospective population-based study of 33,000 men and women. Osteoporos Int. 2006;17:1704.

17. Cornuz J, Feskanich D, Willett WC, Colditz GA. Smoking, smoking cessation, and risk of hip fracture in women. Am J Med. 1999;106:311314.

18. Law MR, Hackshaw AK. A meta-analysis of cigarette smoking, bone mineral density and risk of hip fracture: recognition of a major effect. BMJ. 1997;315:841-6.

19. Valtola A, Honkanen R, Kröger H, Tuppurainen M, Saarikoski S, et al. Lifestyle and other factors predict ankle fractures in perimenopausal women: a population-based prospective cohort study. Bone. 2002:30:238-42.

20. Compston JE, Watts NB, Chapurlat R, Cooper C, Boonen S, et al. Obesity is not protective against fracture in postmenopausal women: GLOW. Am J Med. 2011;124:1043-50.

21. Nielson CM, Marshall LM, Adams AL, Leblanc ES, Cawthon PM, et al. BM and fracture risk in older men: the osteoporotic fractures in men study (MrOS). J Bone Miner Res. 2011;26:496-502.

22. Klotzbuecher CM, Ross PD, Landsman PB, lii TAA, Berger M. Patients with prior fractures have an increased risk of future fractures: a summary of the literature and statistical synthesis. J Bone Miner Res. 2000;15:721-39.

23. Kanis $J A$, Johnell $O$, Laet $C D$, Johansson $H$, Oden $A$, et al. A meta-analysis of previous fracture and subsequent fracture risk. Bone. 2004:35:375-82.

\section{Publisher's Note}

Springer Nature remains neutral with regard to jurisdictional claims in published maps and institutional affiliations.
Ready to submit your research? Choose BMC and benefit from:

- fast, convenient online submission

- thorough peer review by experienced researchers in your field

- rapid publication on acceptance

- support for research data, including large and complex data types

- gold Open Access which fosters wider collaboration and increased citations

- maximum visibility for your research: over $100 \mathrm{M}$ website views per year

At BMC, research is always in progress.

Learn more biomedcentral.com/submissions 